Subscriber access provided by Library, Special Collections and Museums, University of Aberdeen

\title{
Article
}

\section{Acute consumption of flavan-3-ol-enriched dark chocolate affects human endogenous metabolism}

Luisa Martha Ostertag, Mark Philo, Ian J Colquhoun, Henri S Tapp, Shikha Saha, Garry G. Duthie, E. Kate Kemsley, Baukje de Roos, Paul A. Kroon, and Gwénaëlle Le Gall

J. Proteome Res., Just Accepted Manuscript • DOI: 10.1021/acs.jproteome.7b00089 • Publication Date (Web): 06 Jun 2017

Downloaded from http://pubs.acs.org on June 15, 2017

\section{Just Accepted}

"Just Accepted" manuscripts have been peer-reviewed and accepted for publication. They are posted online prior to technical editing, formatting for publication and author proofing. The American Chemical Society provides "Just Accepted" as a free service to the research community to expedite the dissemination of scientific material as soon as possible after acceptance. "Just Accepted" manuscripts appear in full in PDF format accompanied by an HTML abstract. "Just Accepted" manuscripts have been fully peer reviewed, but should not be considered the official version of record. They are accessible to all readers and citable by the Digital Object Identifier (DOI®). "Just Accepted" is an optional service offered to authors. Therefore, the "Just Accepted" Web site may not include all articles that will be published in the journal. After a manuscript is technically edited and formatted, it will be removed from the "Just Accepted" Web site and published as an ASAP article. Note that technical editing may introduce minor changes to the manuscript text and/or graphics which could affect content, and all legal disclaimers and ethical guidelines that apply to the journal pertain. ACS cannot be held responsible for errors or consequences arising from the use of information contained in these "Just Accepted" manuscripts. 


\section{Acute consumption of flavan-3-ol-enriched dark chocolate affects human endogenous metabolism}

Luisa M. Ostertag ${ }^{1,2}$, Mark Philo ${ }^{1}$, Ian J. Colquhoun ${ }^{1}$, Henri S. Tapp ${ }^{1}$, Shikha Saha ${ }^{1}$, Garry G. Duthie ${ }^{2}$, E. Kate Kemsley ${ }^{1}$, Baukje de Roos ${ }^{2}$, Paul A. Kroon ${ }^{1}$, Gwénaëlle Le Gall $^{1 *}$

${ }^{1}$ Quadram Institute Bioscience, Norwich Research Park, Norwich NR4 7UA, UK

${ }^{2}$ Rowett Institute of Nutrition and Health, University of Aberdeen, Aberdeen AB24 3FX, UK

*gwenaelle.legall@quadram.ac.uk

Tel: $+44(0) 1603255280$

Fax: $+44(0) 1603507723$ 


\section{ABSTRACT}

Flavan-3-ols and methylxanthines have potential beneficial effects on human health including reducing cardiovascular risk. We performed a randomized controlled cross-over intervention trial to assess the acute effects of consumption of flavan-3-ol-enriched dark chocolate, compared with standard dark chocolate and white chocolate, on the human metabolome. We assessed the metabolome in urine and blood plasma samples collected before and at $2 \mathrm{~h}$ and $6 \mathrm{~h}$ after consumption of chocolates in 42 healthy volunteers using a non-targeted metabolomics approach. Plasma samples were assessed and showed differentiation between time points with no further separation among the three chocolate treatments. Multivariate statistics applied to urine samples could readily separate the postprandial time points and distinguish between the treatments. Most of the markers responsible for the multivariate discrimination between the chocolates were of dietary origin. Interestingly, small but significant level changes were also observed for a subset of endogenous metabolites. ${ }^{1} \mathrm{H}$ NMR revealed that flavan-3-ol-enriched dark chocolate and standard dark chocolate reduced urinary levels of creatinine, lactate, some amino acids and related degradation products and increased the levels of pyruvate and 4hydroxyphenylacetate, a phenolic compound of bacterial origin. This study demonstrates that an acute chocolate intervention can significantly affect human metabolism.

Keywords: NMR, MS, metabolomics, chocolate, metabolism, health, flavonoids, methylxanthines

\section{INTRODUCTION}

Dark chocolate contains at least two groups of bioactive substances, flavan-3-ols and methylxanthines. Well known flavan-3-ols include catechin, epicatechin gallate, epigallocatechin, epigallocatechin gallate, proanthocyanidins, theaflavins, thearubigins and they are regarded as functional food ingredients ${ }^{1}$. The most well-known methylxanthines are theobromine, caffeine and theophylline. Dark chocolate is enriched in theobromine, with lesser amounts of caffeine and practically no theophylline ${ }^{2}$. 
Flavan-3-ols have various organoleptic properties such as astringency, bitterness, sourness, and sweetness. They also have several beneficial health effects by acting as antioxidant, anticarcinogen, antimicrobial, anti-viral, and neuro-protective agents. They are also known to affect several measures of cardiovascular health, including blood pressure, vascular function $^{3}$, platelet function ${ }^{4,5}$, plasma lipids and lipid peroxidation in humans.

The bioactive effects of methylxanthines are mainly mediated by the so-called adenosine receptor blockers ${ }^{6}$. They may improve lung function ${ }^{2}$. Methylxanthines increase the thermogenic capacity of adipose tissue ${ }^{7}$. There is also a synergistic interaction between caffeine and catechins in increasing thermogenesis on brown adipose tissue ${ }^{8}$.

Very few studies have identified the fate of cocoa components in humans or rodents ${ }^{9,10}$ and such information may help to identify the bioactive compounds. Recently non-targeted approaches in plasma and urine were employed to assess the changes in the host and microbial metabolome after cocoa consumption in human subjects ${ }^{11,12}$. Martin et al. ${ }^{12}$ used Nuclear Magnetic Resonance (NMR) and Mass Spectrometry (MS) approaches to examine human fasted plasma and urine samples to assess the chronic effects of regular consumption of dark chocolate. This study focused on endogenous metabolites involved in energy homeostasis and stress responses but lacked a control group. Llorach et al. ${ }^{11}$ on the other hand, used a non-targeted Liquid Chromatography (LC)/MS method to identify metabolites up to $24 \mathrm{~h}$ after ingestion of a cocoa drink in 10 subjects but the focus was on the metabolites found in the cocoa product, the excretion of the polyphenols ingested and their products.

Previously, we performed a randomized controlled human trial (clinicaltrials.gov; NCT01099150) to evaluate the effect of flavan-3-ol-enriched dark chocolate, standard dark chocolate and white chocolate on platelet function in healthy subjects ${ }^{13}$. Both flavan-3-olenriched dark chocolate and white chocolate, improved several measures of postprandial 
platelet function in a gender-specific way although the specific bioactive compounds could not be determined.

In the current analysis, we employed samples from the same study to assess the effects of acute consumption of flavan-3-ol-enriched dark chocolate, in comparison with standard dark chocolate and white chocolate, on both plasma and urinary proton NMR ( ${ }^{1} \mathrm{H}$ NMR) profiles and urinary MS profiles in 42 healthy humans having fasted $\geq 10 \mathrm{~h}$ overnight. Postprandial assessment of the human metabolome by such complementary techniques provides further insights into both the metabolism of flavan-3-ols and methylxanthines in the human body and the effects these plant bioactives have on endogenous metabolism.

\section{MATERIAL AND METHODS}

Subjects and study design

Recruitment of subjects $(n=42)$ and details of the crossover study design were reported previously ${ }^{13}$.The study was carried out in accordance with the ethical principles of the Declaration of Helsinki and Good Clinical Practice. The study was approved by the Ethics Committee of the Rowett Institute of Nutrition and Health, University of Aberdeen (reference number 09-002) following review by the North of Scotland Research Ethics Committee. This trial was registered at clinicaltrials.gov as NCT01099150. Volunteers were informed about the purpose and the risks of the study, and written informed consent was obtained from all subjects before participation.

The details are summarised in the Supporting Information Material and Methods, Figure S1 and Tables S1 and 2.

Urine and blood sampling and creatinine assay 
Sampling and storage of biofluid samples was previously described ${ }^{13}$, as was measurement of creatinine in urine. Relevant details are supplied in the Supporting Information.

\section{Extraction and analysis of flavonoid content of the chocolate bars}

First, lipids were removed from chocolate samples as described by Cooper et al. ${ }^{14}$. This included the extraction of defatted and dried chocolate powder using $70 \%$ aqueous methanol containing $0.1 \mathrm{mg} / \mathrm{mL}$ galangin (282200, Sigma-Aldrich) as internal standard. Samples were heated to $70{ }^{\circ} \mathrm{C}$ for $20 \mathrm{~min}$. Supernatants were filtered and filtrates from each sample were analyzed by normal-phase HPLC as described previously. Samples were analyzed in duplicate and the resulting flavonoid contents of the chocolate bars are shown in (Table S3).

\section{NMR procedure}

Urine samples were thawed at room temperature and prepared for ${ }^{1} \mathrm{H}$ NMR spectroscopy by mixing $500 \mu \mathrm{L}$ urine with $50 \mu \mathrm{L}$ phosphate buffer $\left(1.2 \mathrm{mmol} / \mathrm{L} \mathrm{K}_{2} \mathrm{HPO}_{4}\right.$ and $0.3 \mathrm{mmol} / \mathrm{L}$ $\mathrm{KH}_{2} \mathrm{PO}_{4}, \mathrm{pH} 7.4$ ) made up in $100 \% \mathrm{D}_{2} \mathrm{O}$ and containing $0.005 \%$ sodium azide and 3.3 $\mathrm{mmol} / \mathrm{L}$ TSP (3-trimethylsilyl propionate) as chemical shift reference. The sample was shaken and $500 \mu \mathrm{L}$ transferred into a $5 \mathrm{~mm}$ NMR tube for spectral acquisition. ${ }^{1} \mathrm{H}$ NMR spectra were recorded at $600 \mathrm{MHz}$ on a Bruker Avance spectrometer (Bruker BioSpin $\mathrm{GmbH}$, Rheinstetten, Germany) running TOPSPIN 2.0 software and fitted with a cryoprobe and a 60 slot autosampler. The acquisition order was randomized with respect to collection date and sample codes. Each ${ }^{1} \mathrm{H}$ NMR spectrum was acquired with 128 scans, $90^{\circ}$ pulses (14 $\mu \mathrm{s})$, spectral width $8012.8 \mathrm{~Hz}$, acquisition time $2.04 \mathrm{~s}$ and relaxation delay $2.0 \mathrm{~s}$. The noesygppr1d pre-saturation sequence was used to suppress the residual water signal with low power selective irradiation at the water frequency during the relaxation delay and mixing time (0.01s). Spectra were transformed with zero filling and $0.3 \mathrm{~Hz}$ line broadening, manually phased, baseline corrected and referenced by setting the TSP methyl signal to $0 \mathrm{ppm}$. 
Metabolites were identified using information found in the literature ${ }^{15-17}$, on the web (Human Metabolome Database, http://www.hmdb.ca/), using Chenomx software, and by use of the 2D-NMR methods COSY, HSQC, and HMBC.

Plasma $(200 \mu \mathrm{L})$ was mixed with $400 \mu \mathrm{L}$ saline solution $(0.9 \% \mathrm{w} / \mathrm{v} \mathrm{NaCl}$ in $90 \% / 10 \%$ $\mathrm{H}_{2} \mathrm{O} / \mathrm{D}_{2} \mathrm{O}$ ) and $500 \mu \mathrm{L}$ were transferred to an NMR tube. Proton NMR spectra were measured at $300 \mathrm{~K}$ using the same NMR equipment. Spectra were acquired using the Bruker cpmgpr1d water suppression pulse sequence, with $32 \mathrm{k}$ data points, spectral width 20.8 ppm, acquisition time $1.36 \mathrm{~s}$, relaxation delay $2 \mathrm{~s}, 90^{\circ}$ pulses $(11 \mu \mathrm{s})$, spin-echo delay $0.4 \mathrm{~ms}$, loop number 300 (giving a total echo time $=240 \mathrm{~ms}$ ) and 128 transients per spectrum. Free induction decays were zero filled and exponential line broadening of $1 \mathrm{~Hz}$ was applied prior to Fourier transformation. Proton NMR spectra were referenced to the anomeric $\alpha$-glucose signal ( $\delta 5.234$ ppm).

\section{NMR data analysis}

NMR Spectra were prepared for statistical analysis using the Bruker AMIX software v3.9. The spectra were divided along the horizontal axis into variable width "buckets" (or bins) using the AMIX graphical editor to draw buckets that include, where possible, recognizably complete individual peaks or multiplets. The intensities within each bucket were summed, divided by the bucket width and the bucket intensities were normalized to the same total intensity for each sample to give the final bucket table. Regions with only background noise, the urea peak and the water resonance were not included in the buckets. This gave matrices of 368 samples $\times 380$ buckets for the urine NMR spectra and 363 samples by 101 buckets for the plasma spectra.

HPLC-TOF MS analysis

A subset of 240 urine samples ( 0 and 6-h post chocolate) was defrosted and vortex mixed before sampling. A portion of urine $(1 \mathrm{~mL})$ was centrifuged for $5 \mathrm{~min}$ at $9600 \mathrm{~g}$ and $150 \mu \mathrm{L}$ 
of the supernatant was transferred to a glass vial to which MilliQ water ( $450 \mu \mathrm{L})$ was added. The sample was vortex mixed. A portion of each individual sample (35 $\mu \mathrm{L})$ was taken and pooled to make a quality control sample (PQC) representative of all samples in the sample set. Sample analysis used an Agilent 1100 HPLC coupled to a Bruker Daltonics MicroTOF. Sample $(5 \mu \mathrm{L})$ was injected onto a Phenomenex Gemini C18 column (150 x $2.1 \mathrm{~mm}, 3.0 \mu \mathrm{m}$ at $25 \stackrel{\circ}{\circ}$ ) with a flow rate of $250 \mu \mathrm{L} / \mathrm{min}$. A gradient of $100 \% \mathrm{~A}$ (MilliQ water $+0.1 \%$ formic acid) and $0 \%$ B (acetonitrile $+0.1 \%$ formic acid) was applied increasing B to $15 \%$ over 5 min and then to $95 \%$ over $15 \mathrm{~min}$ and held at $95 \%$ for $4 \mathrm{~min}$. The PQC was injected for the first three runs and after each set of six injections for each batch (samples were randomized into batches of 50 samples). The TOF scan was over 90-1000 amu in positive ESI mode. Mass calibration was performed for each sample using reference masses of sodium formate ion clusters to give a mass accuracy of $5 \mathrm{ppm}$. The Bruker raw data files were converted to NetCDF and the metabolite feature data presented in the manuscript were generated entirely using the Bioconductor (http://www.bioconductor.org/software) packages XCMS (v 1.22.1) ${ }^{18}$ running with default parameters under $R$ (v 2.11.0). XCMS finds and integrates peaks within small time and mass windows and produces a table of integrated intensities for a set of features (identified by combined mass retention time labels) that are common to all samples. Features are reported if they occur in more than half the samples in at least one of the groups (e.g. control, treatment) so that intensities of features from say flavan-3-ol metabolites may be close to zero in baseline samples. Each feature has an associated median accurate mass which may be used for putative identification of species present via database search (e.g. MZedDB, http://maltese.dbs.aber.ac.uk:8888/hrmet/index.html ${ }^{19}$ or from relevant literature ${ }^{11}$. A total of 2900 features were extracted for subsequent data analysis.

\section{Data Analysis}


Multivariate statistical analysis (Principal Component Analysis, PCA) was carried out using the PLS Toolbox v5.5 (Eigenvector Research Inc.,Wenatchee, WA) running within Matlab, v7.6 (The MathWorks Inc., Natick, MA). Autoscaling was applied to the columns of the bucket table. The same procedure was applied to the integrated intensities in the XCMS table with the mass retention time features taking the place of NMR buckets as variates.

Univariate analyses were carried out on individual variates (NMR or LC/MS) in GraphPad Prism v5.01 (GraphPad Software, San Diego, CA) using the Kruskal-Wallis test with Dunn's post-test. The same software was used to plot the results of these analyses. A comprehensive set of univariate analyses was also carried out on all buckets for the urine NMR data using an in-house Matlab routine. The comparison of metabolic responses to the three different chocolate types was performed on bucketed NMR spectra that were area normalised followed by two stages of probabilistic scaling ${ }^{21}$. First, the three baseline (time $t$ $=0$ ) spectra for an individual were scaled to their mean. Second, spectra collected at times $\mathrm{t}$ $=2 \mathrm{~h}$ and $\mathrm{t}=6 \mathrm{~h}$ were scaled to their corresponding adjusted baseline. Post-ingestion difference spectra were calculated by subtraction of their corresponding adjusted baselines. For both post-ingestion time points the differences in the spectral response of each bucket were ranked by their Mack-Skillings statistic ${ }^{22,23}$. The top 162 \& 223 buckets were found to be significantly different at $2 \mathrm{~h}$ and $6 \mathrm{~h}$ respectively, based on a FDR of $q=0.05$ [22], using $p$-values based on $10^{7}$ within-block permutations ${ }^{22,23}$. The significance of the differences in response at each bucket was also estimated from within-block permutations (Table S5).

\section{RESULTS}

We recruited 42 healthy subjects, each receiving three acute treatments (flavan-3-olenriched dark chocolate (EDC), standard dark chocolate low in flavan-3-ols (DC), or white 
chocolate (WC) containing no flavan-3-ols) in random order. The three intervention days were separated by two washout periods of at least two weeks. This crossover design provided optimal statistical power as each subject acted as their own control.

Dietary markers mainly contribute to the discrimination of the metabolite profiles

Plasma NMR spectra were assessed by PLSDA and showed differentiation between Oh and later time points but no discrimination between the three chocolate treatments (Figure S2). Differentiation was caused by elevation of lactate at $2 \mathrm{~h}$ and aspartate, acetoacetate, acetone and $\beta$-hydroxybutyrate levels at $6 \mathrm{~h}$ after ingestion ${ }^{24}$.

A series of Principal Component Analysis (PCA) models were created from urine ${ }^{1} \mathrm{H}$ NMR and LC/MS data to assess whether there was separation between dietary treatments at $0 \mathrm{~h}$, 2 and $6 \mathrm{~h}$ post-ingestion and between the different time points for each treatment (Figure 1). LC/MS data from the $2 \mathrm{~h}$ samples was not recorded hence only the $0 \mathrm{~h}$ and $6 \mathrm{~h}$ groups were analysed. Three 4 group PCA models were constructed: controls at $0 \mathrm{~h}, \mathrm{EDC}-2 \mathrm{~h}, \mathrm{DC}-2 \mathrm{~h}$ and WC-2h; controls at $0 \mathrm{~h}$, EDC-6h, DC-6h and WC-6h both for NMR data and controls at $0 \mathrm{~h}$, EDC-6h, DC-6h and WC-6h for LC/MS data. All three models showed partial overlap of dark chocolate groups (EDC and DC) but clear discrimination between dark chocolate groups, WC and the baseline group (Oh) (Figure $1 \mathrm{a}-\mathrm{c}$ ). Three treatment-based PCA models (EDC, DC and WC) applied to 3 groups (0,2 and 6h postprandially) also showed a clear separation between $0 \mathrm{~h}$ and post-ingestion scores but the scores at 2 and $6 \mathrm{~h}$ post-ingestion groups overlapped (Figure 1d-f and Figure S3 a-c).

The discrimination of samples from the EDC group and to some extent the DC group versus the baseline group (Oh) and WC group (seen on PC4 in Figure 1a and PC2 in Figure 2b) was largely due to an increase in the intensity of buckets containing signals from epicatechin derivatives, theobromine and its methylxanthine derivatives (Figure S3 d-e) in the EDC and DC groups. 
(a)

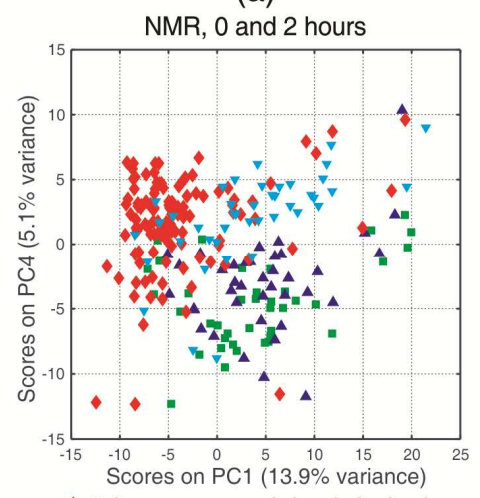

(d)

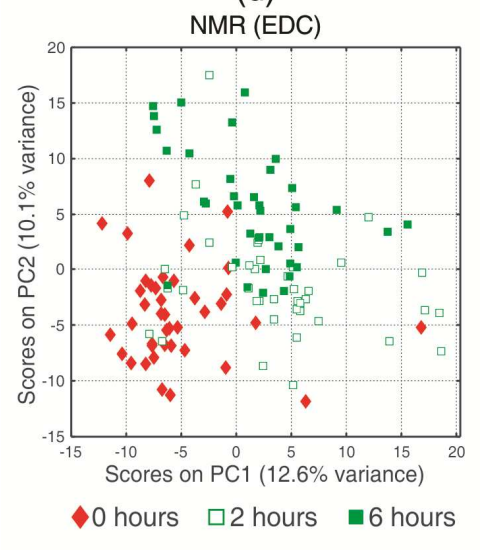

(b)

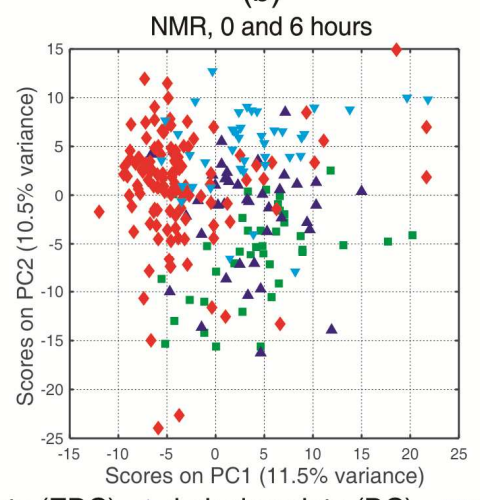

(e)

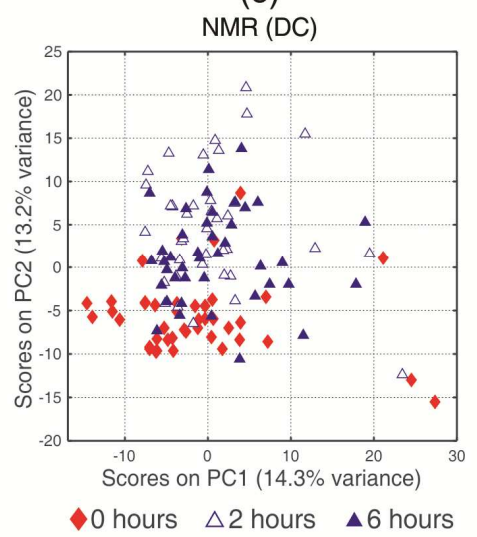

(c)

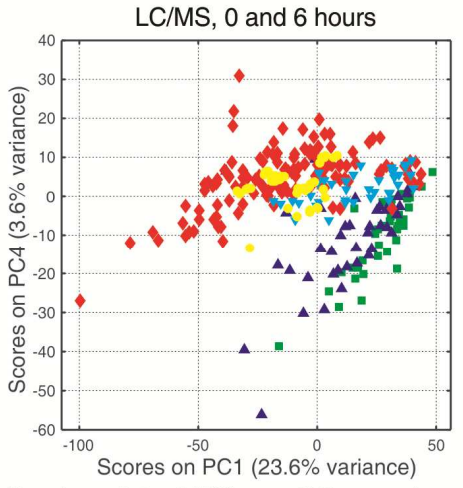

QC samples

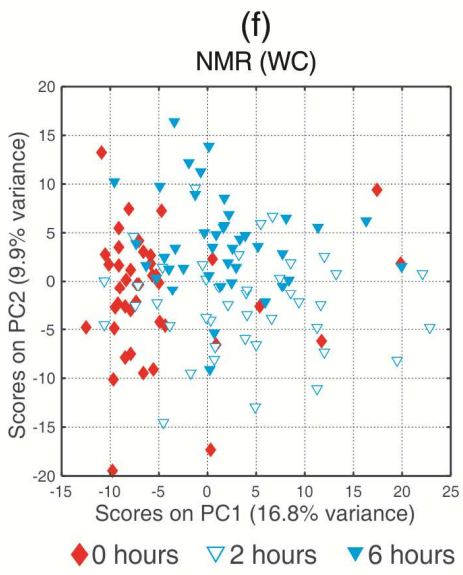

Figure 1.

Assignment of the dietary markers and their levels across the three chocolate treatments

Epicatechin derivatives and methylxanthines were detected in urine samples by both ${ }^{1} \mathrm{H}$ NMR and LC/TOF-MS. Comparison of HSQC and COSY spectra of 6h EDC and WC urines (same volunteer) revealed many new peaks in the EDC spectra that were not present in the WC. The signals were assigned as theobromine or epicatechin metabolites using information from the HMDB, literature, or via spiking (theobromine itself). Several buckets between 3.5 and 4.0 ppm containing signals arising from 3- and 7-methylxanthines and theobromine (3,7dimethylxanthine) as well as the singlets from the corresponding xanthine purine rings at 8.03, 7.86 and $7.91 \mathrm{ppm}$ were all strong markers in the urines from volunteers having ingested either DC or EDC (Figure 2 and Table 1). 
Thanks to its higher sensitivity, numerous additional dietary metabolites were detected by LC/MS as reported previously ${ }^{11}$. Derivatives of theobromine (Figure 3) were identified in the urines after DC and EDC consumption, namely 3- and 7-methyluric acids, 3,7-dimethyluric acid, 6-amino-5[N-methylformylamino]-1-methyluracil (AMMU), as well as intact theobromine (Table 2). Several metabolites indicative of EDC and DC consumption were identified including hydroxynicotinate, caffeine and vannilloylglycine. Several metabolites of catechins were also detected, i.e. epicatechin monosulfate, 4-hydroxy-5-(3,4-dihydroxyphenyl)valerate, the glucuronide and sulfate metabolites of 5-(3',4'-dihydroxyphenyl)- $\gamma$-valerolactone and 3'-methoxy-4'-hydroxyphenylvalerolactone and its glucuronide. Those metabolites were all observed $6 \mathrm{~h}$ post-ingestion and their levels significantly increased compared with levels at $0 \mathrm{~h}$. There was a decrease in hippurate levels from $0 \mathrm{~h}$ to $6 \mathrm{~h}$ postprandial after consumption of all types of chocolate (Figure 3). A set of features that were significantly enhanced in white chocolate was noticed although the identification of the compounds remains to be established (Table S4). 


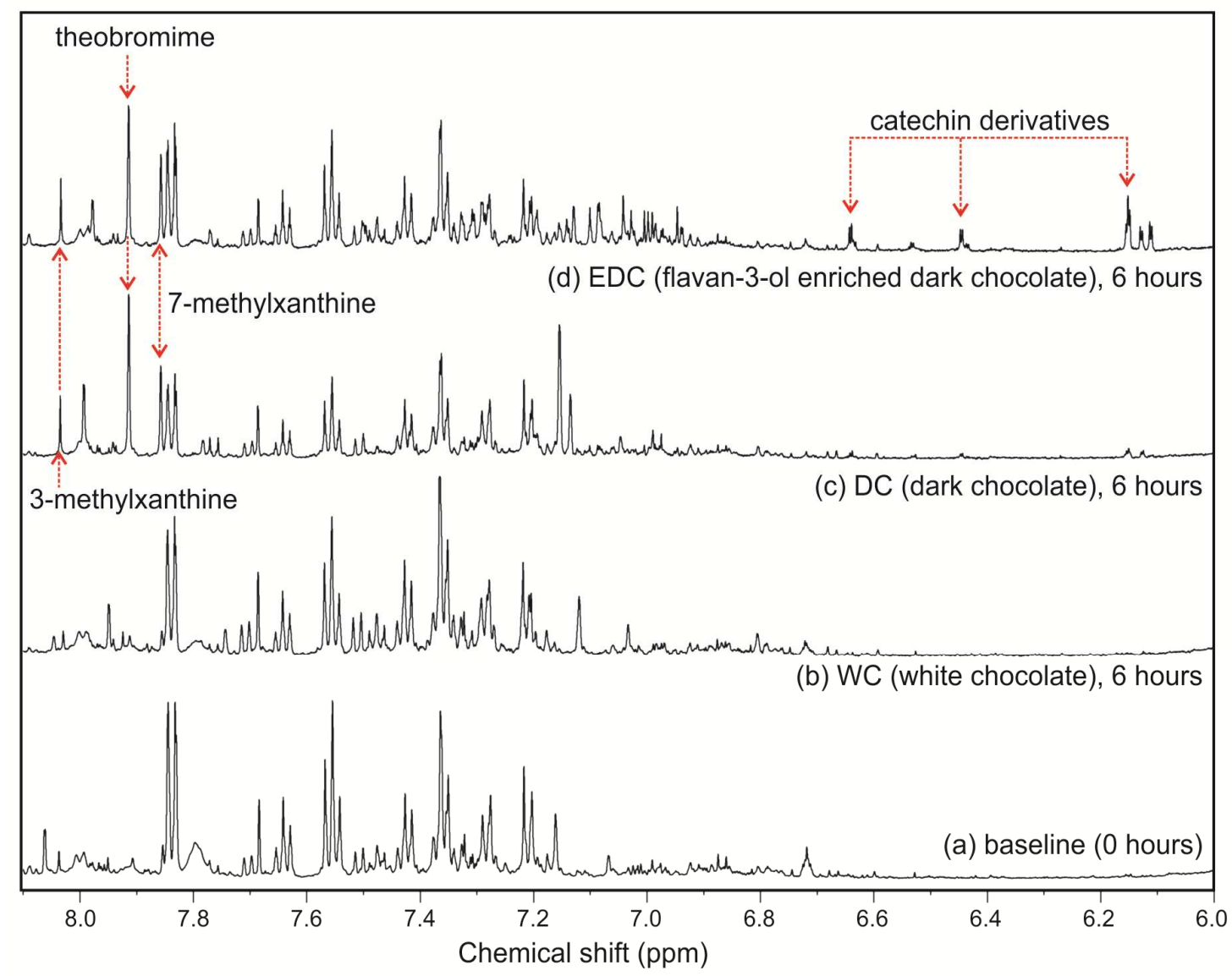

Figure 2. 
(a) methyluric

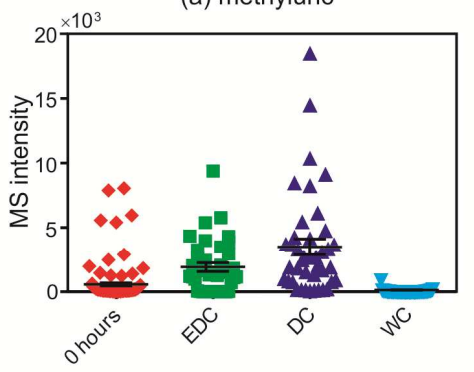

(d) epicatechin sulfate

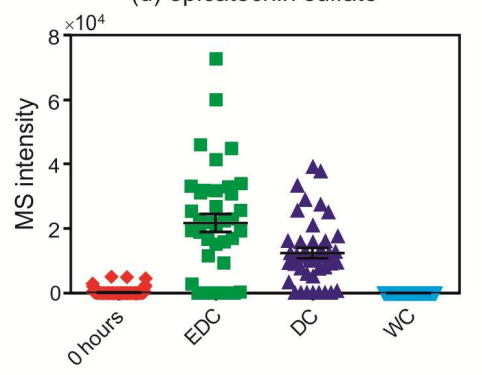

(b) methylxanthine

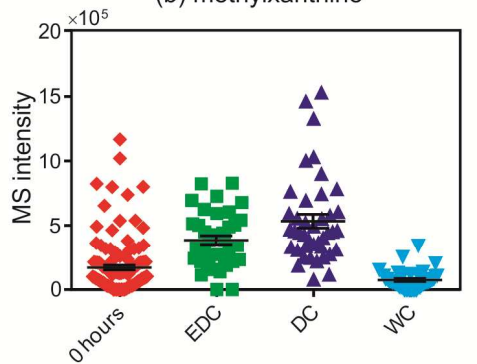

(e) hydroxydihydroxyphenylvalerate

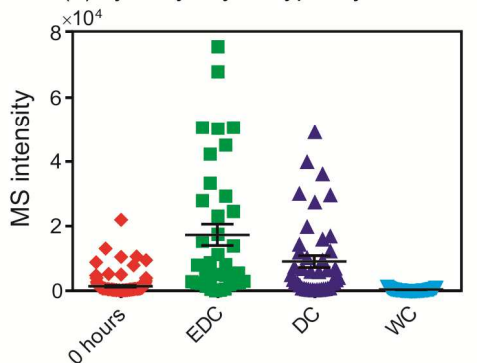

(c) theobromine

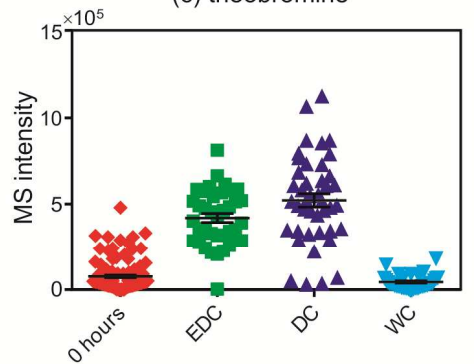

(f) hippurate

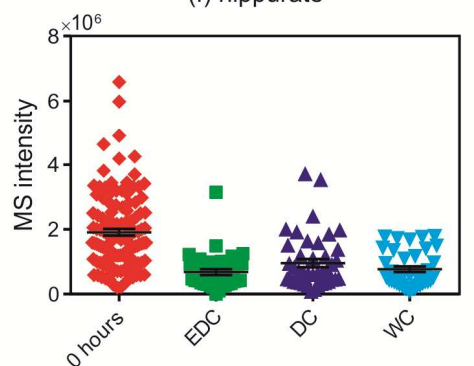

(g)<smiles>C1CC1</smiles>

(1,3, 7-Trimethylxanthine)<smiles>Cn1c(=O)c2c(ncn2C)n(C)c1=O</smiles>

$\mathrm{m} / \mathrm{z} 195$ at $12.5 \mathrm{~min}$

3,7-dimethyluric acid
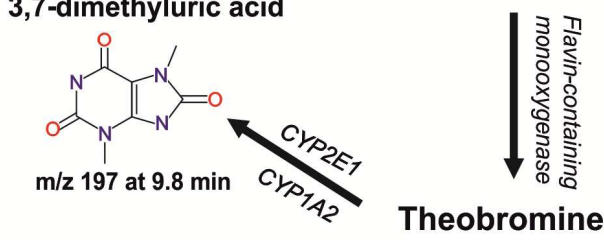

Theobromine (3,7-Dimethylxanthine)

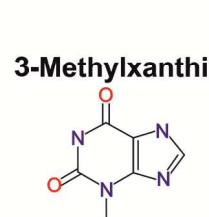

$8.03 \mathrm{ppm} / 144.8 \mathrm{ppm}$

$3.53 \mathrm{ppm} / 32.3 \mathrm{ppm}$

$\mathrm{m} / \mathrm{z} 167$ at $9.7 \mathrm{~min}$

3-methyluric acid<smiles></smiles>

$\mathrm{m} / \mathrm{z} 183$ at $9.2 \mathrm{~min}$ 3.49 ppm / 31.9 ppm $3.94 \mathrm{ppm} / 36.2 \mathrm{ppm}$ $\mathrm{m} / \mathrm{z} 181$ at $10.7 \mathrm{~min}$
Paraxanthine

(1,7-dimethyxanthine)<smiles></smiles>

7-Methylxanthine

7-methyluric acid
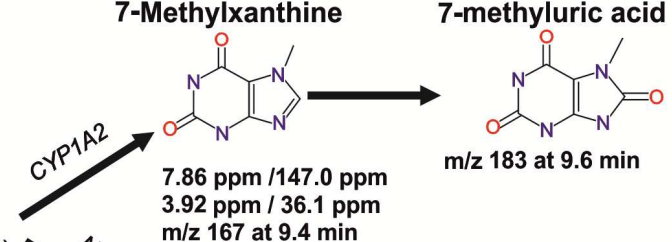

$\mathrm{m} / \mathrm{z} 183$ at $9.6 \mathrm{~min}$

$\mathrm{m} / \mathrm{z} 167$

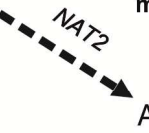

AFMU: 5-acetylamino-6-formylamino-3-methyluracil

\section{Figure 3.}

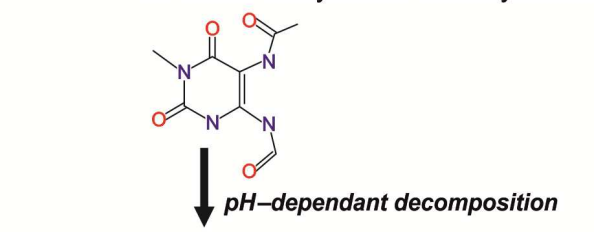

5-Acetylamino-6-amino-3-methyluracil

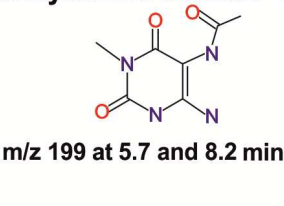

$\mathrm{m} / \mathrm{z} 199$ at 5.7 and $8.2 \mathrm{~min}$

5-Acetylamino-6-amino-3-methyluracil 


\section{Concentration of flavanol-3-ols and methylxanthines in chocolate.}

The combined caffeine and theobromine concentrations were quite similar in both dark chocolates. The flavanol-3-ol enriched chocolate had a combined content of $1.12 \%$ whilst the standard dark chocolate contained $1.23 \%$. (Table S1). The enriched dark chocolate contained $1.5 \%$ total flavonoids compared to $0.64 \%$ in the standard dark chocolate (Table S3). Neither methylxanthines nor flavonoids were detected in the white chocolate.

\section{Changes in endogenous metabolite levels across the three chocolate treatments}

The urinary ${ }^{1} \mathrm{H}$ NMR spectra recorded were segmented into 380 buckets and univariate analyses were carried out on the bucket intensities. Of these buckets, 223 had a p-value lower than 0.05 when the three chocolate treatments were compared at $6 \mathrm{~h}$ (see Table S5). The markers with the lowest $p$ values were assigned to catechin and xanthine derivatives. Interestingly, a subset of endogenous metabolites was affected by the chocolate intake, mainly by the two dark chocolates (Table 3). Urinary levels of several amino acids (Ala, Val, Gly) and organic acids (2- and 3-hydroxyisobutyrate, 3-hydroxyisovalerate) were significantly decreased $6 \mathrm{~h}$ after intake of both dark chocolates compared with white chocolate and all followed the same trend: mean level in flavan-3-ol-enriched dark chocolate < dark chocolate $<$ white chocolate. Additionally, a few energy compounds also followed the same trend, namely creatinine, $\mathrm{N}^{1}$-methylnicotinamide (NMA) and lactate. Interestingly pyruvate followed an inverse trend where levels were increased by flavan-3-ol-enriched dark chocolate and dark chocolate compared with white chocolate. Levels of tyrosine and its microbial product (para-hydroxyphenylacetate) were also elevated after consumption of both dark chocolates (Table 3). Trends for selected markers can be found in Figure 4. 
(a) creatinine, $3.05 \mathrm{ppm}$

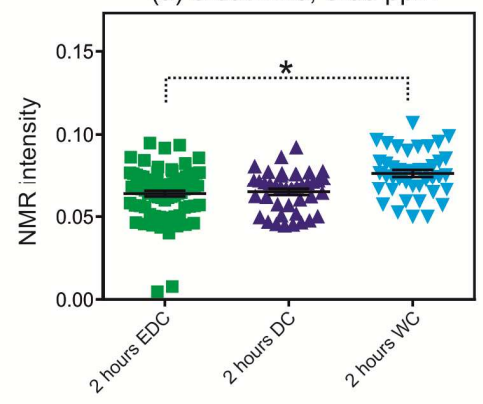

(d) NMA, 4.48ppm

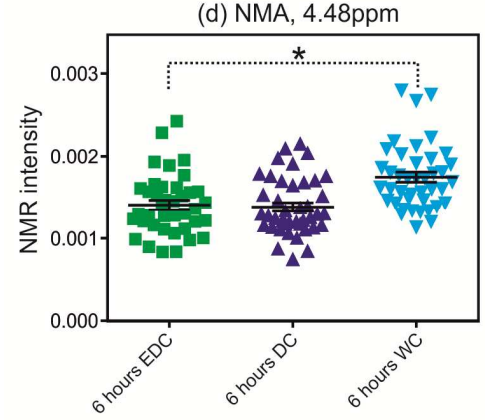

(b) creatinine, $4.07 \mathrm{ppm}$

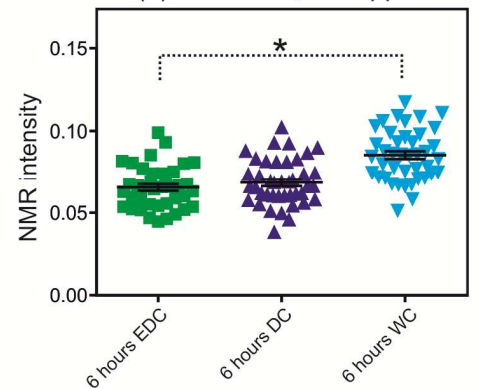

(e) tyrosine, 6.90ppm

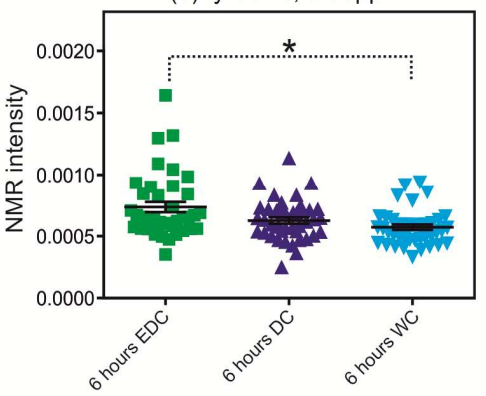

(c) creatinine, KONELAB assay
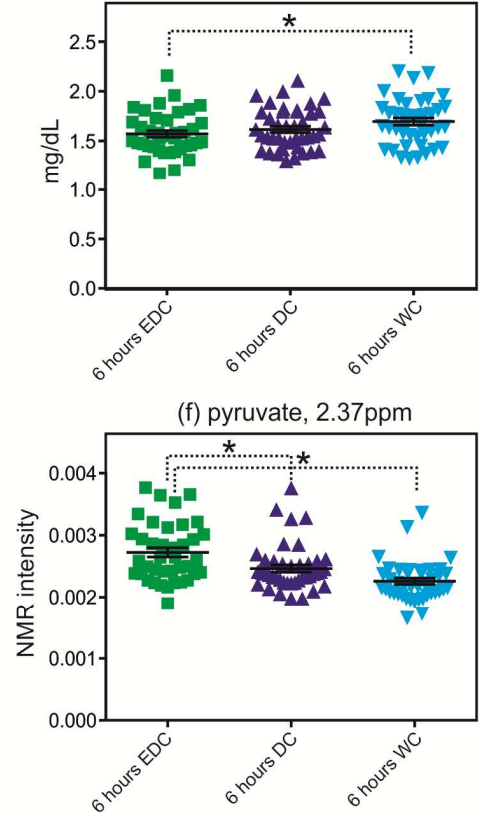

Figure 4.

Changes in metabolite levels associated with gender and age

Differences in levels of the main xanthine metabolites (3- and 7-methylxanthine and theobromine) and the buckets at $6.11,6.13$ and $6.15 \mathrm{ppm}$ reflecting catechin derivatives were investigated further by subdividing the treatment groups according to gender, BMI and age, at 2- and 6-h post chocolate. Only theobromine excretion levels showed a significant difference with respect to gender, with higher levels being excreted by females compared with males. The gender differences were being observed for both dark chocolates at the $6 \mathrm{~h}$ and for standard dark chocolate at the $2 \mathrm{~h}$ time point. There was also an effect of the age on the levels of the same metabolite with a higher excretion for volunteers aged 29 or younger compared with volunteers older than 54 (Figure 5). 
(a)

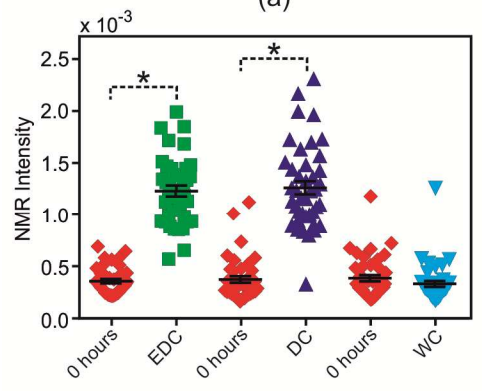

(b)

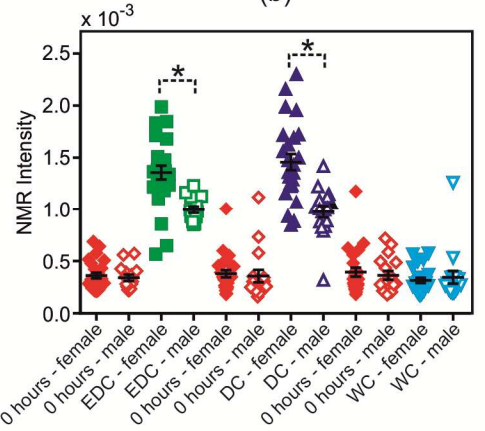

(c)

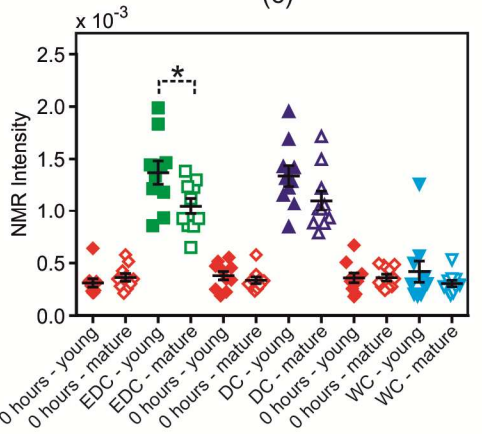

Figure 5.

\section{DISCUSSION}

In this study we assessed acute effects of consumption of flavan-3-ol-enriched dark chocolate in comparison with a standard dark and a white chocolate on plasma and urinary ${ }^{1} \mathrm{H}$ NMR profiles and urinary MS profiles in healthy humans. Both urinary and plasma profiles showed wide-scale metabolite composition changes post-chocolate intake. Multivariate and univariate analyses coupled to metabolite identification revealed that the major differences between treatments were found in urine and changes were related to both intake markers as well as markers of endogenous metabolism.

There was no differentiation between the three treatment groups in the plasma ${ }^{1} \mathrm{H}$ NMR profiles contrary to the many changes detected in the urinary profiles. No theobromine or catechin derived metabolites were found because plasma concentrations of these were under the detection limit for NMR.

Changes detected in the urinary profiles principally affected a number of NMR buckets between 3.00 and $4.00 \mathrm{ppm}$, and in the regions of 6.10 and $8.00 \mathrm{ppm}$ after both dark chocolate treatments. Those signals were attributed to metabolized compounds of dietary origin (catechin ${ }^{25}$ and methylxanthine ${ }^{26}$ derivatives). Interestingly Martin et al $^{12}$ detected an increase in levels of two unknown singlets at 7.85 and $7.91 \mathrm{ppm}$ after one week of chronic intake of dark chocolate which were most likely peaks arising from 7-methylxanthine and 
theobromine (see Table 1). The levels of an unknown at $3.39 \mathrm{ppm}$ detected in the present study were also increased in their study. Caffeine itself was not detected in the urinary spectra because the levels were too low to be detected. For comparison the abundance of theobromine in the dark chocolates was six times that of caffeine (supplementary Table 3) yet only theobromine and two main products ( 3 and 7-methyl xanthines) were detected by ${ }^{1} \mathrm{H}$ NMR. 6-amino-5[N-methylformylamino]-1-methyluracil (AMMU) is the main degradation product after caffeine intake ${ }^{27}$. In our study, 3-methylxanthine, 7-methylxanthine and AMMU are the main urinary products of theobromine ${ }^{26}$ (Figure $3 g$ ). Caffeine degradation may have marginally contributed to the AMMU levels detected by LC/MS. The LC/MS on $6 \mathrm{~h}$ urines demonstrated changes in metabolites of polyphenols and alkaloids metabolites and also showed the occurrence of microbial metabolites. Our results are in agreement with other studies $^{11,25}$.

However, there was no increase in hippurate levels in our study although this metabolite of microbial origin has been recognized as the main excretion product from polyphenols such as catechins and from green and black tea consumption ${ }^{28,29}$.

There was an increase of para-hydroxyphenylacetate (HPA) $6 \mathrm{~h}$ after ingestion of both dark chocolates. Hydroxyphenylacetate is related to food intake and breakdown processes by gut microbiota ${ }^{30}$. It originates from dietary phenolic compounds, including the catechins contained in dark chocolate. The increase of HPA was accompanied with an increase of tyrosine, an abundant component of cacao seeds ${ }^{11}$.

We did not observe changes in levels of citric acid cycle compounds such as succinate or citrate but, as in a study on consumption of black tea polyphenols ${ }^{31}$, we saw an increase of pyruvate in urine. Additionally, we saw a reduction in lactate at $6 \mathrm{~h}$ post-intake of flavan-3-olenriched dark chocolate. The lactate levels increased at $6 \mathrm{~h}$ for WC compared to $\mathrm{Oh}$ and to EDC or DC at $6 \mathrm{~h}$. Whilst we cannot elucidate the mechanisms of such changes based on metabolomics results alone, it is possible that, glycolysis and/or gluconeogenesis might be 
enhanced by the catechin-rich chocolate thus increasing levels of excreted pyruvate ${ }^{32,33}$. Concomitantly, a large intake of catechins might have affected anaerobic respiration, leading to a reduced production of lactate. Furthermore, the urinary levels of four glucogenic amino acids, arginine, valine, alanine and glycine, were reduced after consumption of flavan-3-olenriched dark chocolate, suggesting a possible redirection of the energy metabolism towards gluconeogenesis ${ }^{33}$ following catechin intake (Table 3).

The urinary levels of both creatinine and $\mathrm{N}^{1}$-methylnicotinamide (NMA) were reduced following intake of both dark chocolates but creatinine was increased by WC at $6 \mathrm{~h}$. The levels of creatinine and NMA in WC were higher than EDC or DC at 6h as shown in Figure 4. Creatinine is a clearance product from phosphocreatine $(\mathrm{PCr})$ which itself is a phosphate donor for sudden adenosine triphosphate (ATP) demand and NMA arises from dietary niacin and from tryptophan metabolism ${ }^{34}$. Wang et $a l^{35}$ proposed a link between creatinine urinary levels, oxidative stress and modulation of oxidative stress by antioxidants which could be attributed to catechins in both dark chocolates. A decrease in creatinine may be associated with a better regulation of the PCr pool and ATP usage. Note that a decrease in creatinine has already been observed by Martin et $\mathrm{al}^{12}$. This similarity indicates that both acute and chronic intake of dark chocolate may affect the energy metabolism in a similar way.

A decrease in NMA would indicate an upregulation towards the production of $\mathrm{NAD}^{+}$and energy expenditure ${ }^{36}$. Also NMA is an activator of prostacyclin $\left(\mathrm{PGI}_{2}\right)$ production which may regulate thrombotic as well as inflammatory processes in the endothelial vascular system via anti-platelet effects ${ }^{37,38}$. In our case, decreases in creatinine and NMA urinary levels may indicate effects on metabolic regulation bringing potential health benefits through the action of chocolate bioactive ingredients.

Martin et al ${ }^{12}$ showed that dark chocolate had an effect on the energy metabolism and on metabolites from gut microbiota. Products from the gut microbiota are commonly found in biological fluids including urine, plasma or faecal waters ${ }^{39}$. These include methylamine, 
dimethylamine (DMA), trimethylamine (TMA), and trimethylamine-N-oxide (TMAO) and related metabolites (dimethylglycine) which may originate from dietary choline.

We observed a urinary decrease of DMA in urine $6 \mathrm{~h}$ after ingestion of both dark chocolates. Dimethylamine is a product of TMA and TMAO. It is difficult to assess if a reduction of DMA is beneficial to health. Wang et al ${ }^{40}$ reported that supplementation of mice with choline, TMAO or betaine promoted upregulation of multiple macrophage scavenger receptors linked to atherosclerosis, and supplementation with choline or TMAO promoted atherosclerosis. Therefore, it appears that lower endogenous levels of methylamines may be beneficial to health.

The short chain hydroxy acids, 3-hydroxyisovalerate, 2-hydroxyisobutyrate and 3hydroxyisobutyrate, were reduced following intake of both dark chocolates but increased from $0 \mathrm{~h}$ to $6 \mathrm{~h}$ after WC. These acids are normally found at low levels in urine of healthy individuals ${ }^{41}$ and at high levels in urine and blood of patients suffering from branched-chain organic acidurias ${ }^{42}$ or other acidosis ${ }^{43}$. Both 3-hydroxyisovalerate and 3-hydroxyisobutyrate are intermediates in the catabolism of branched amino acids such as leucine and valine and 2-hydroxyisobutyrate has been reported as being a gut metabolite increased in the urine of healthy humans eating a diet high in proteins ${ }^{41}$. Newgard et al ${ }^{44}$ compared the blood profiles of obese and lean humans and showed a link between a branched-chain amino acid-related metabolite signature and increased catabolism of branched amino acids and correlation with insulin resistance. In our case, the reduced branched amino acids catabolism may be part of the change in energy metabolism observed after eating dark chocolate. Regulating the catabolism of these amino acids may be a positive benefit on glucose metabolism.

Caffeine and theobromine are the most abundant methylxanthines in chocolate and their physiological effects are well recognised ${ }^{2}$. They are extensively metabolized (urinary 
recovery of $<2 \%$ ) and are known to be metabolized by cytochrome P450 (CYP450) enzymes during phase II excretion ${ }^{27,45}$.

In this study, females excreted on average almost twice as much theobromine as males $6 \mathrm{~h}$ after intake of both dark chocolates and there was also a significant dependence of theobromine excretion on age with flavan-3-ol-enriched dark chocolate treatment. Some previous studies reported no gender effect on elimination following an intake of caffeine, theobromine or theophylline ${ }^{27,46,47}$ while others reported the inverse ${ }^{45}$. Additionally, Agarwal ${ }^{48}$ showed that in vitro arginine ${ }^{8}$-vasopressin (AVP) levels in blood from male and female donors differed and that theophylline and a related xanthine could interfere with the platelet aggregation capacity of AVP in human platelet-rich plasma. This result points to a multiple factor effect (including gender) and/or expression of CYP450 enzymes (CYP1A2 in particular ${ }^{47}$ ) on compounds and metabolized products which in turn could affect the host metabolism.

\section{Conclusion}

These effects may have arisen from consumption of both the flavanol-3-ols and the methylxanthines. In many cases there was similar response to both dark chocolates and the increased flavonoid content did not show any dose response even though the enriched dark chocolate contained some 2.4 times the flavonoid content of the standard dark chocolate.

In summary, this NMR and MS-based metabolomic study has shown that dietary markers are traceable in the urine of healthy individuals after an acute intake of flavan-3-ol-enriched dark and standard dark chocolate. Bioactive compounds and metabolized products were also found to have an effect on the endogenous metabolism and the gut microbial activity affecting in particular several pathways relating to energy metabolism and the nicotinate pool.

Associated Content available

Subjects 
Study design

Biofluid and blood sampling

Creatinine assay

Figure S1. Flow chart of the study design

Figure S2. PC scores, PC loadings from PCA analysis on blood plasma data

Figure S3. PC scores, PC loadings from PCA analysis on urine data

Table S1. Nutritional composition of chocolate bars

Table S2. Baseline characteristics for study subjects

Table S3. Flavonoid content of chocolate bars

Table S4. Urinary MS markers for white chocolate

Table S5. NMR bucket markers for the comparison between 4 groups: $0 \mathrm{~h}$, EDC, DC and WC treatment groups

\section{COMPETING FINANCIAL INTERESTS}

None of the authors declared a conflict of interest.

\section{ACKNOWLEDGMENTS}

This work was supported by the Biotechnology \& Biological Sciences Research Council (BBSRC) Competitive Strategic Grant and the Scottish Government Rural and Environment Research and Analysis Directorate (RERAD). All chocolates were specifically produced for this study and provided free of charge by Natraceutical Group, Valencia, Spain.

We thank the volunteers who participated in the study.

\section{AUTHOR CONTRIBUTIONS}

The authors' responsibilities were as follow: LMO, GGD, PAK and BDR: designed and conducted the nutritional intervention; GLG: designed the metabolomic analyses; MP and SS: performed the MS analysis; LMO and GLG: performed the NMR analysis; IJC and GLG: analyzed the NMR and MS data; EKK and HST: performed some statistical analyses; GLG: 
interpreted the NMR and MS data; GLG: wrote the manuscript and all authors: provided comments, read and approved the final manuscript.

\section{REFERENCES}

1. Aron, P. M. \& Kennedy, J. A. Flavan-3-ols: Nature, occurrence and biological activity. Mol. Nut. and Food Res. 2008, 52, 79-104.

2. Franco, R., Oñatibia-Astibia, A. \& Martínez-Pinilla, E. Health benefits of methylxanthines in cacao and chocolate. Nutrients 2013, 5, 4159-4173.

3. Hooper, L. et al. Flavonoids, flavonoid-rich foods, and cardiovascular risk: a meta-analysis of randomized controlled trials. Am. J. Clin Nutr.2008, 88, 38-50.

4. Ostertag, L. M., O'Kennedy, N., Kroon, P .A., Duthie, G. G.\& De Roos, B. Impact of dietary polyphenols on human platelet function--a critical review of controlled dietary intervention studies. Mol. Nutr. Food Res. 2010, 54, 60-81.

5. Bachmair, E. M., Ostertag, L. M., Zhang, X., \& de Roos, B. Dietary manipulation of platelet function. Pharmacol Ther. 2014, 144, 97-113.

6. Fredholm, B. B. \& Persson, C. G. Xanthine derivatives as adenosine receptor antagonists. Eur. J. Pharmacol. 1982, 81, 673-676.

7. Dulloo, A. G., Seydoux, J., Girardier, L. Potentiation of the thermogenic antiobesity effects of ephedrine by dietary methylxanthines: adenosine antagonism or phosphodiesterase inhibition? Metabolism 1992, 41, 1233-1141.

8. Dulloo, A. G., Seydoux, J., Girardier, L., Chantre, P. \& Vandermander, J. Green tea and thermogenesis: interactions between catechin-polyphenols, caffeine and sympathetic activity. Int. J. Obes. Relat. Metab. Disord. 2000, 24, 252-258. 
9. Rios, L. Y. et al. Chocolate intake increases urinary excretion of polyphenol-derived phenolic acids in healthy human subjects. Am. J. Clin. Nutr. 2003, 77, 912-918.

10. Urpi-Sarda, M. et al. Epicatechin, procyanidins, and phenolic microbial metabolites after cocoa intake in humans and rats. Anal. Bioanal. Chem. 2009, 394, 1545-1556.

11. Llorach, R., Urpi-Sarda, M., Jauregui, O., Monagas, M., \& Andres-Lacueva, C. An LCMS-based metabolomics approach for exploring urinary metabolome modifications after cocoa consumption. J. Proteome Res. 2009, 8, 5060-5068.

12. Martin, F. P. et al. Metabolic effects of dark chocolate consumption on energy, gut microbiota, and stress-related metabolism in free-living subjects. J. Proteome Res. 2009, 8, 5568-5579.

13. Ostertag, L. M. et al. Flavan-3-ol-enriched dark chocolate and white chocolate improve acute measures of platelet function in a gender-specific way - a randomized-controlled human intervention trial. Mol. Nut. Food Res. 2013, 57, 181-202.

14. Cooper, K. A. et al. Rapid reversed phase ultra-performance liquid chromatography analysis of the major cocoa polyphenols and inter-relationships of their concentrations in chocolate. J. Agric. Food Chem. 2007, 55, 2841-2847.

15. Nicholson, J. K., Foxall, P .J. D., Spraul, M., Farrant, R. D. \& Lindon, J. C. 750 MHz 1H and 1H-13C NMR spectroscopy of human blood plasma. Anal. Chem. 1995, 67, 793-811.

16. Bouatra, S. et al. The human urine metabolome, PLoS One 2013, 8, e73076.

17. Calvani, R. et al. Fecal and urinary NMR-based metabolomics unveil an aging signature in mice Exp. Gerontol. 2014, 49, 5-11. 
18. Smith, C. A., Want, E. J., O'Maille, G., Abagyan, R., \& Siuzdak, G. XCMS: processing mass spectrometry data for metabolite profiling using nonlinear peak alignment, matching, and identification. Anal. Chem. 2006, 78, 779-787.

19. Draper, J. et al. Metabolite signal identification in accurate mass metabolomics data with MZedDB, an interactive $\mathrm{m} / \mathrm{z}$ annotation tool utilising predicted ionisation behaviour 'rules'. BMC Bioinformatics. 2009, 10, 227-242.

20. Rajalahti, T. et al.. Biomarker discovery in mass spectral profiles by means of selectivity ratio plot. Chemom. Intell. Lab. Sys. 2009, 95, 35-48.

21. Dieterle, F., Ross, A., Schlotterbeck, G., \& Senn, H. Probamilistic quotient normalization as robust method to account for dilution of complex biological Mixtures. Application in ${ }^{1} \mathrm{H}$ NMR metabonomics. Anal. Chem. 2006, 78, 4281-4290).

22. Mack, G. A., \& Skillings, J. H. A Friedman-type rank test for main effects in a two-factor ANOVA. J. Amer. Statist. Assoc. 1980, 75, 947-951.

23. Hollander, M., \& Wolfe, D. A. Nonparametric statistical methods. 2nd edition, Chichester, Wiley, 1999, p 343-353.

24. Bales, J.R., Bell. J.D., Nicholson, J.K., Sadler, P,J. ${ }^{1} H$ NMR studies of urine during fasting: excretion of ketone bodies and acetylcarnitine. Magn. Reson. Med. 1986, 3, 849856.

25. Fardet $A$ et al. A liquid chromatography-quadrupole time-of-flight (LC-QTOF)-based metabolomic approach reveals new metabolic effects of catechin in rats fed high-fat diets. $J$. Proteome Res. 2008, 7, 2388-2398.

26. Tarka, S. M., Arnaud, M.., Dvorchik, B. H. \& Vesell, E. S. Theobromine kinetics and metabolic disposition. Clin. Pharmacol. Ther. 1983, 34, 546-555. 
27. Arnaud, M. J. Pharmacokinetics and metabolism of natural methylxanthines in animal and man. Handb. Exp. Pharmacol. 2011, 200, 33-91.

28. Clifford, M.N., Copeland, E.L., Bloxsidgem, J.P., Mitchell, L.A. Hippuric acid as a major excretion product associated with black tea consumption. Xenobiotica 2000, 30, 317-326.

29. Mulder, T.P., Rietveld, A.G., van Amelsvoort, J.M. Consumption of both black tea and green tea results in an increase in the excretion of hippuric acid into urine. Am. J. Clin. Nutr. 2005, 81, 256S-260S.

30. Li, M. et al. Symbiotic gut microbes modulate human metabolic phenotypes. Proc. Natl. Acad. Sci. U S A. 2008, 105, 2117-2122.

31. Daykin, C. A. et al. Nuclear magnetic resonance spectroscopic based studies of the metabolism of black tea polyphenols in humans. J. Agric. Food Chem. 2005, 53, 1428-1434.

32. Van Dorsten, F.A., Daykin, C.A., Mulder, T.P., Van Duynhoven, J.P. Metabonomics approach to determine metabolic differences between green tea and black tea consumption J. Agric. Food Chem. 2005, 54, 6929-6938.

33. Khakimov, B et al. New Nordic diet versus average Danish diet: A randomized controlled trial revealed healthy long-term effects of the New Nordic diet by GC-MS blood plasma metabolomics J. Proteome Res. 2016, 15, 1939-1954.

34. Takahashi, K., Okunom A., Fukuwatarim T. \& Shibatam, K. Comparison of the nicotinamide catabolism among rat strains. Biosci. Biotechnol. Biochem. 2009, 73, 274-279.

35. Wang, Y. et al. A metabonomic strategy for the detection of the metabolic effects of chamomile (Matricaria recutita L.) ingestion. J. Agric. Food Chem. 2005, 53, 191-196.

36. Kraus et al. Nicotinamide $N$-methyltransferase knockdown protects against diet-induced obesity. Nature 2014, 208, 258-264. 
37. Przygodzki, T., Kazmierczak, P., Sikora, J. \& Watala, C. 1-methylnicotinamide effects on the selected markers of endothelial function, inflammation and haemostasis $3 n$ diabetic rats Eur. J. Pharmacol. 2010, 640, 157-162.

38. Mogielnicki, A., Kramkowski, K., Pietrzak, L. \& Buczko, W. N-methylnicotinamide inhibits arterial thrombosis in hypertensive rats. J. Physiol. Pharmacol. 2007, 58, 515-527.

39. Martin, F.P. et al. Probiotic modulation of symbiotic gut microbial-host metabolic interactions in a humanized microbiome mouse model. Mol. Syst. Biol. 2008, 4, 157.

40. Wang, $Z$ et al. Gut flora metabolism of phosphatidylcholine promotes cardiovascular disease. Nature 2011, 472, 57-63.

41. Yap, I. K. et al. Metabolome-wide association study identifies multiple biomarkers that discriminate north and south Chinese populations at differing risks of cardiovascular disease: INTERMAP study. J. Proteome Res. 2010, 9, 6647-6654.

42. Ogier de Baulny, H. \& Saudubray, J. M. Branched-chain organic acidurias. Semin. Neonatol. 2002, 7, 65-74.

43. Shigematsu, Y. et al. Changing plasma and urinary organic acid levels in a patient with isovaleric acidemia during an attack. Pediatr. Res. 1982, 16, 771-775.

44. Newgard et al. A Branched-Chain Amino Acid-Related Metabolic Signature that Differentiates Obese and Lean Humans and Contributes to Insulin Resistance. Cell Metab. 2009, 9, 311-326.

45. Relling, M. V., Lin, J. S., Ayers, G. D. \& Evans, W. E. Racial and gender differences in Nacetyltransferase, xanthine oxidase, and CYP1A2 activities. Clin. Pharmacol. Ther. 1992, $52,643-658$.

46. Begas E., Kouvaras, E., Tsakalof, A., Papakosta, S. \& Asprodini, E. K. In vivo evaluation of CYP1A2, CYP2A6, NAT-2 and xanthine oxidase activities in a Greek population sample 
by the RP-HPLC monitoring of caffeine metabolic ratios. Biomed Chromatogr. 2007, 21, 190200.

47. Chung, W. G., Kang, J. H., Park, C. S., Cho, M. H. \& Cha, Y. N. Effect of age and smoking on in vivo CYP1A2, flavin-containing monooxygenase, and xanthine oxidase activities in Koreans: determination by caffeine metabolism. Clin Pharmacol Ther. 2000, 67, 258-266.

48. Agarwal, K.C. Modulation of vasopressin actions on human platelets by plasma adenosine and theophylline: gender differences. J. Cardiovasc. Pharmacol. 1993, 21, 10121018.

Table 1. Exogenous urinary NMR markers for Enriched dark (EDC) and dark chocolate (DC) 6 hours after intake

Fold: EDC compared to white chocolate (WC) the control group underlined chemical shift: used for data analysis

\begin{tabular}{|c|c|c|c|c|c|}
\hline $\begin{array}{l}\text { Bucket } \\
\text { group }\end{array}$ & $\delta_{\mathrm{H}} \mathrm{ppm}$ & $\delta_{C} p p m$ & $\begin{array}{l}\text { Metabolite } \\
\text { identification }\end{array}$ & $\begin{array}{l}p \text { value t-test } \\
\text { EDC vs WC }\end{array}$ & $\begin{array}{l}\text { Fold } \\
\text { EDC/ } \\
\text { WC }\end{array}$ \\
\hline 1 & 2.59 & 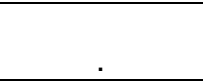 & $\begin{array}{c}\text { catechin derivatives } \\
(\mathrm{C} \text { ring })\end{array}$ & 4E-08 & 1.4 \\
\hline 2 & 2.79 & 30.1 & $\begin{array}{c}\text { epicatechin } \\
\text { derivatives ( } \mathrm{C} \text { ring) }\end{array}$ & 2.E-19 & 1.5 \\
\hline 3 & $\begin{array}{c}2.94,2.95,2.98 \\
\quad \underline{3.00}, 3.01\end{array}$ & 30.3 & $\begin{array}{l}\text { epicatechin/polymer } \\
\text { derivatives (C ring) }\end{array}$ & 2.E-18 & 2.0 \\
\hline 4 & 3.39 & 31.9 & $?$ & 2.E-21 & 2.0 \\
\hline 5 & 3.49 & 31.9 & theobromine & 3.E-11 & 3.0 \\
\hline 6 & 3.53 & 32.2 & 3-methylxanthine & 8.E-09 & 1.7 \\
\hline 7 & 3.92 & 36.2 & 7-methylxanthine & 7.E-14 & 2.4 \\
\hline 8 & 3.94 & 36.2 & theobromine & 2.E-10 & 2.0 \\
\hline 9 & 4.00 & . & $\begin{array}{c}\text { catechin derivatives } \\
(\mathrm{C} \text { ring })\end{array}$ & 4.E-10 & 0.8 \\
\hline 10 & $5.08,5.11,5.14$ & $80.8,81.2$ & $\begin{array}{l}\text { polymer catechin } \\
\text { derivatives }(\mathrm{C} \text { ring })\end{array}$ & $\begin{array}{l}\text { buckets not } \\
\text { drawn }\end{array}$ & \\
\hline 11 & $\begin{array}{c}6.11,6.13,6.15 \\
\underline{6.44}, 6.64\end{array}$ & $\begin{array}{l}\text { 98.1, 98.8, } \\
103.4,105.0\end{array}$ & $\begin{array}{c}\text { all catechin } \\
\text { derivatives ( } A \text { ring } \\
\text { mainly) }\end{array}$ & $9 . E-22$ & 11.8 \\
\hline 12 & $6.94-\underline{-7.31}$ & & $\begin{array}{c}\text { all catechin } \\
\text { derivatives ( } B \text { ring } \\
\text { mainly) }\end{array}$ & 2.E-12 & 1.7 \\
\hline 13 & 7.86 & 147.0 & 7-methylxanthine & 5.E-12 & 3.5 \\
\hline 14 & 7.91 & 146.8 & theobromine & 6.E-22 & 3.7 \\
\hline 15 & 8.03 & 144.8 & 3-methylxanthine & 2.E-13 & 2.2 \\
\hline
\end{tabular}


Table 2. Urinary MS markers for Enriched dark (EDC) and dark chocolate (DC) 6 hours after intake Fold: EDC compared to white chocolate (WC) the control group

* ion seen in the raw data but not detected by the deconvolution approach

\begin{tabular}{|c|c|c|c|c|c|c|}
\hline $\begin{array}{l}\text { Marker } \\
\text { group }\end{array}$ & Marker ions & $\begin{array}{c}\text { Metabolite } \\
\text { identification }\end{array}$ & $\begin{array}{l}\text { Retention } \\
\text { time } \\
\text { (min) }\end{array}$ & $\begin{array}{c}\text { Theoretical } \\
\text { mass } \\
{[\mathrm{M}+\mathrm{H}]+}\end{array}$ & $\begin{array}{c}\text { p } \\
\text { value } \\
\text { t-test } \\
\text { EDC } \\
\text { vs WC }\end{array}$ & $\begin{array}{l}\text { Fold } \\
\text { EDC/ } \\
\text { WC }\end{array}$ \\
\hline 1 & $140.035[\mathrm{M}+\mathrm{H}]+$ & hydroxynicotinic & 4.3 & 140.034 & 2.E-07 & 4 \\
\hline 2 & $\begin{array}{c}199.084[\mathrm{M}+\mathrm{H}]+ \\
171.087[\mathrm{M}+\mathrm{H}- \\
\mathrm{H} 2 \mathrm{O}]_{+}\end{array}$ & AMMU & $5.7 ; 8.2$ & 199.083 & $\begin{array}{l}3 . E-12 \\
2 . E-09\end{array}$ & $\begin{array}{l}5 \\
4\end{array}$ \\
\hline 3 & 185.091 & $?$ & 7.2 & & $6 . \mathrm{E}-11$ & 3 \\
\hline 4 & 260.064 & $?$ & 8.4 & & $5 . \mathrm{E}-13$ & 24 \\
\hline 5 & $\begin{array}{c}321.085[\mathrm{M}+\mathrm{H}]+ \\
343.071[\mathrm{M}+\mathrm{Na}]+\end{array}$ & $?$ & 8.8 & & $\begin{array}{l}2 . E-12 \\
8 . E-13\end{array}$ & $\begin{array}{c}8 \\
750\end{array}$ \\
\hline 6 & $\begin{array}{c}547.15[3 \mathrm{M}+\mathrm{H}]+ \\
365.101[2 \mathrm{M}+\mathrm{H}]+ \\
183.052[\mathrm{M}+\mathrm{H}]+\end{array}$ & 7 and 3-methyl-uric & 9.2 & $\begin{array}{l}365.095 \\
183.052\end{array}$ & $\begin{array}{l}7 . E-05 \\
7 . E-03 \\
4 . E-04\end{array}$ & $\begin{array}{c}29 \\
2 \\
2\end{array}$ \\
\hline 7 & $\begin{array}{c}167.057[\mathrm{M}+\mathrm{H}]+ \\
333.108[2 \mathrm{M}+\mathrm{H}]+\end{array}$ & $\begin{array}{c}7 \text { and 3- } \\
\text { methylxanthine }\end{array}$ & 9.5 & $\begin{array}{l}167.056 \\
333.105\end{array}$ & $\begin{array}{l}5 . E-11 \\
1 . E-09\end{array}$ & $\begin{array}{l}5 \\
9\end{array}$ \\
\hline 8 & $197.057[\mathrm{M}+\mathrm{H}]+$ & dimethyluric & 9.9 & 197.0669 & 2.E-09 & 3 \\
\hline 9 & $\begin{array}{c}181.072[\mathrm{M}+\mathrm{H}]+ \\
399.099[2 \mathrm{M}+\mathrm{K}]+\end{array}$ & theobromine & 10.7 & $\begin{array}{l}181.072 \\
399.093 \\
\end{array}$ & $\begin{array}{l}2 . E-17 \\
2 . E-14 \\
\end{array}$ & $\begin{array}{l}10 \\
8\end{array}$ \\
\hline 10 & $\begin{array}{c}420.091 \\
425.110 \\
209.082[\mathrm{M}+\mathrm{H}- \\
\left.\mathrm{H}_{2} \mathrm{O}\right]_{+}\end{array}$ & $\begin{array}{l}\text { 4-hydroxy-5-(3,4- } \\
\text { dihydroxyphenyl)- } \\
\text { valeric acid }\end{array}$ & 11.8 & 209.081 & $\begin{array}{c}1 . E-05 \\
3 . E-05 \\
.{ }^{*}\end{array}$ & $\begin{array}{l}42 \\
8 \\
*\end{array}$ \\
\hline 11 & $\begin{array}{c}226.073[\mathrm{M}+\mathrm{H}]+ \\
151.042[\mathrm{M}+\mathrm{H}- \\
\text { glycine }]+\end{array}$ & vanniloylglycine & 12.1 & $\begin{array}{l}226.071 \\
151.040\end{array}$ & $\begin{array}{l}3 . E-08 \\
1 . E-08\end{array}$ & $\begin{array}{l}5 \\
3\end{array}$ \\
\hline 12 & $\begin{array}{l}568.108 \\
547.176\end{array}$ & $?$ & 12.4 & & $\begin{array}{l}2 . E-08 \\
1 . E-06\end{array}$ & $\begin{array}{l}59 \\
16\end{array}$ \\
\hline 13 & $195.089[\mathrm{M}+\mathrm{H}]+$ & caffeine & 12.5 & 195.088 & 4.E-05 & 2 \\
\hline 14 & $\begin{array}{c}385.116 \\
407.115[\mathrm{M}+\mathrm{Na}]+ \\
209.124[\mathrm{M}+\mathrm{H}- \\
\text { GlcA }]+\end{array}$ & $\begin{array}{c}5-\left(3^{\prime}, 4^{\prime}-\right. \\
\text { dihydroxyphenyl)- } \\
\text { valerolactone } \\
\text { glucuronide }\end{array}$ & 13.3 & 385.113 & $\begin{array}{l}1 . \mathrm{E}-06 \\
9 . \mathrm{E}-10 \\
1 . \mathrm{E}-06\end{array}$ & $\begin{array}{l}61 \\
60 \\
9\end{array}$ \\
\hline 14 & $\begin{array}{c}399.135[\mathrm{M}+\mathrm{H}]+ \\
223.096[\mathrm{M}+\mathrm{H}- \\
\text { GlcA }]+ \\
421.122[\mathrm{M}+\mathrm{Na}]+\end{array}$ & $\begin{array}{l}\text { 3'-methoxy-4'- } \\
\text { hydrxyphenylvalerolact } \\
\text { one glucuronide }\end{array}$ & 13.4 & $\begin{array}{l}399.129 \\
223.096\end{array}$ & $\begin{array}{l}1 . E-04 \\
3 . E-05 \\
\text { 2.E-06 }\end{array}$ & $\begin{array}{l}8 \\
8 \\
19\end{array}$ \\
\hline 15 & $\begin{array}{c}369.113[\mathrm{M}+\mathrm{H}]+ \\
391.106[\mathrm{M}+\mathrm{Na}]+\end{array}$ & O-Feruloylquinate? & 13.6 & 391.100 & $\begin{array}{l}2 . E-06 \\
5 . E-06\end{array}$ & $\begin{array}{l}19 \\
13\end{array}$ \\
\hline
\end{tabular}




\begin{tabular}{|c|c|c|c|c|c|c|}
16 & $289.040[\mathrm{M}+\mathrm{H}]+$ & $\begin{array}{c}5-\left(3^{\prime}, 4^{\prime}-\right. \\
\text { dihydroxyphenyl- } \\
\text { valerolactone-sulfate }\end{array}$ & 17.7 & 289.038 & $2 . \mathrm{E}-05$ & 23 \\
\hline 17 & 371.044 & epicatechin-O-sulfate & 22.2 & 371.043 & $3 . \mathrm{E}-09$ & 2400 \\
\hline
\end{tabular}

Table 3. Changed in levels of endogenous urinary NMR markers for Enriched dark (EDC) and dark chocolate (DC) 6 hours after intake

Trends: EDC and DC compared to white chocolate (WC) the control group underlined chemical shift: used for data analysis

${ }^{*}$ could correspond to chemical groups from amino acids such as ornithine or citrulline

\begin{tabular}{|c|c|c|c|c|c|c|}
\hline $\begin{array}{l}\text { Marker } \\
\text { group }\end{array}$ & $\delta(p p m)$ & $\begin{array}{c}\text { Metabolite } \\
\text { identification }\end{array}$ & Trends & Class & $\begin{array}{c}\mathbf{p} \\
\text { value } \\
\text { t-test } \\
\text { EDC } \\
\text { vs } \\
\text { WC }\end{array}$ & $\begin{array}{c}\text { Fold } \\
\text { EDC/WC }\end{array}$ \\
\hline 1 & $\frac{3.05}{4.07}$ & creatinine & down & energy metabolism & $2 \mathrm{E}-08$ & 0.8 \\
\hline 2 & $\begin{array}{l}1.68, \\
\underline{1.95} \\
\end{array}$ & arginine & down & amino acid & $8 \mathrm{E}-05$ & 0.9 \\
\hline 3 & $\begin{array}{l}1.00, \\
1.05 \\
\end{array}$ & valine & down & amino acid & $4 \mathrm{E}-06$ & 0.9 \\
\hline 4 & 1.49 & alanine & down & amino acid & $4 \mathrm{E}-05$ & 0.8 \\
\hline 5 & 3.57 & glycine & down & amino acid & $\begin{array}{l}5 . E- \\
03\end{array}$ & 0.8 \\
\hline 6 & 1.78 & unknown at $1.78 \mathrm{ppm}$ & down & ${ }^{*}$ & $2 \mathrm{E}-07$ & 0.8 \\
\hline 7 & 1.88 & unknown at $1.88 \mathrm{ppm}$ & down &.${ }^{*}$ & $9 \mathrm{E}-05$ & 0.9 \\
\hline 8 & $\frac{4.48}{9.28}$ & $\mathrm{~N}$-methylnicotinamide & down & $\begin{array}{l}\text { pyridine, metabolite } \\
\text { of niacin (vitB3) }\end{array}$ & $\begin{array}{c}2 . \mathrm{E}- \\
04\end{array}$ & 0.8 \\
\hline 9 & 2.07 & $\begin{array}{l}\mathrm{N} \text {-acetylated } \\
\text { compounds }\end{array}$ & down & $\begin{array}{l}\text { (phase II and other } \\
\text { pathways) }\end{array}$ & $8 \mathrm{E}-06$ & 0.9 \\
\hline 10 & 2.73 & dimethylamine & down & $\begin{array}{l}\text { amine (bacterial } \\
\text { origin) }\end{array}$ & $\begin{array}{l}3 . \mathrm{E}- \\
02\end{array}$ & 0.9 \\
\hline 11 & 1.28 & 3-hydroxyisovalerate & down & $\begin{array}{l}\text { short chain hydroxy } \\
\text { acid, leucine } \\
\text { catabolism }\end{array}$ & $\begin{array}{c}2 . \mathrm{E}- \\
04\end{array}$ & 0.8 \\
\hline 12 & 1.36 & 2-hydroxyisobutyrate & down & $\begin{array}{l}\text { short chain hydroxy } \\
\text { acid }\end{array}$ & $\begin{array}{c}2 . \mathrm{E}- \\
04\end{array}$ & 0.9 \\
\hline 13 & 1.08 & 3-hydroxyisobutyrate & down & $\begin{array}{l}\text { short chain hydroxy } \\
\text { acid, valine } \\
\text { catabolism }\end{array}$ & $\begin{array}{c}1 . \mathrm{E}- \\
03\end{array}$ & 0.9 \\
\hline 14 & 1.34 & lactate & down & short chain fatty acid & $\begin{array}{c}2 . \mathrm{E}- \\
04\end{array}$ & 0.8 \\
\hline 15 & 2.37 & pyruvate & up & $\begin{array}{c}\text { glycolysis, } \\
\text { gluconeogenesis }\end{array}$ & $2 \mathrm{E}-06$ & 1.2 \\
\hline 16 & 6.86 & $\begin{array}{c}\text { 4-hydroxyphenyl } \\
\text { acetate }\end{array}$ & up & $\begin{array}{l}\text { phenolic compound } \\
\text { (bacterial origin) }\end{array}$ & $\begin{array}{c}7 . E- \\
03\end{array}$ & 1.2 \\
\hline 17 & $\frac{6.90}{7.19}$ & tyrosine & up & amino acid & $\begin{array}{c}1 . \mathrm{E}- \\
03\end{array}$ & 1.3 \\
\hline 18 & 4.4 & unknown at $4.40 \mathrm{ppm}$ & up & & $\begin{array}{c}2 . \mathrm{E}- \\
02\end{array}$ & 1.2 \\
\hline
\end{tabular}




\section{Figure Legends}

Figure 1. PCA score plots from urine samples at baseline $(0 \mathrm{~h})$ and at the specified time for each of the three chocolate treatments (a) NMR $0 \mathrm{~h} \& 2 \mathrm{~h}$, (b) NMR $0 \mathrm{~h} \& 6 \mathrm{~h}$, (c) LC/MS $0 \mathrm{~h}$ \& 6 h. PCA score plots from urinary NMR spectra of 0 -hour, 2-hours and 6-hours samples for flavan-3-ol-enriched dark chocolate (EDC) (d), dark chocolate (DC) (e) and white chocolate (WC) (f)

Figure 2. Partial $600 \mathrm{MHz}{ }^{1} \mathrm{H}$ NMR spectra of urines from one subject: $(A)$ baseline and $(B)$ (D) after treatment indicated at $6 \mathrm{~h}$

Figure 3. MS intensity for markers of enriched dark chocolate (EDC) and dark chocolate (DC) intake and hippurate 6 hours after intake. White (WC) chocolate is the control group. All have $p$ value $<0.0001$ (Kruskal-Wallis test on 4 groups). 0 -hour $n=126$; EDC, 6 -hours $n=38$, DC, 6-hours $n=42$ and WC, 6-hours $n=39$. Selected $m / z$ ions were $m / z$ 183.052, 167.057, 181.072, 371.044, 420.091, 180.066 (a to $f$ respectively). (g) Map of the theobromine pathway. Cytochrome P450 (CYP2E1, CYP1A2) and N-acetyltransferase 2 (NAT2), are involved in the activation or detoxification of various xenobiotic compounds including alkaloid like theobromine (adapted from Arnaud ${ }^{27}$ )

Figure 4. NMR intensity/ concentration of a selection of endogenous urine metabolites for the three chocolate treatments. (all groups) $n=39-42$. Plots are for the times specified from data in NMR buckets (a) creatinine at $3.05 \mathrm{ppm}$, (b) creatinine at $4.07 \mathrm{ppm}$, (c) creatinine (KONELAB assay), (d) $\mathrm{N}^{1}$-methylnicotinamide (NMA) at $4.48 \mathrm{ppm}$, (e) tyrosine at $6.90 \mathrm{ppm}$ and (f) pyruvate at 2.37 ppm. ${ }^{*} p<0.05$ Mann-Whitney test

Figure 5. NMR intensity of theobromine at $7.91 \mathrm{ppm}$ in urines at $0 \mathrm{~h}$ (baseline) or $6 \mathrm{~h}$ (treatments) showing (a) overall variation with treatment, (b) grouping by treatment and gender, (c) grouping by treatment and age (younger $<29$ y, older $>54$ y). (all groups) $n=14$ $42 n=14-42$ per group. Note that because of the crossover design each treatment group has its own baseline $(0 \mathrm{~h})$ samples. ${ }^{*} \mathrm{p}<0.05$ Mann-Whitney test 
For TOC only

(a) methyluric

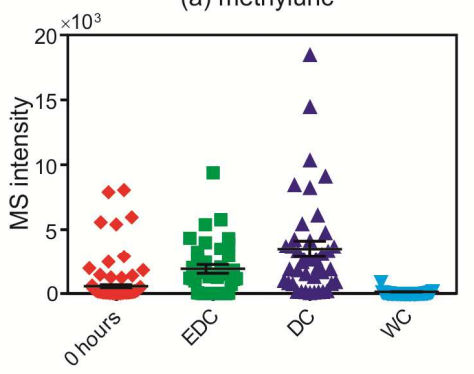

(d) epicatechin sulfate

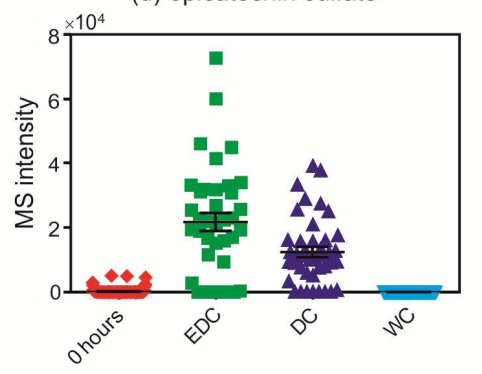

(b) methylxanthine

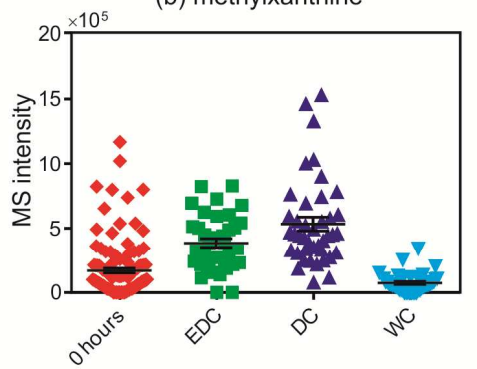

(e) hydroxydihydroxyphenylvalerate

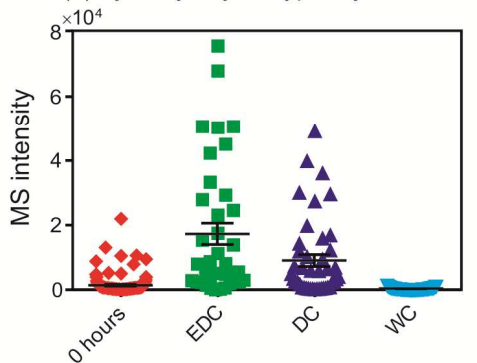

(c) theobromine

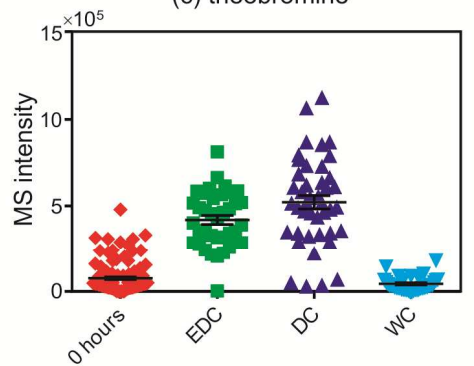

(f) hippurate

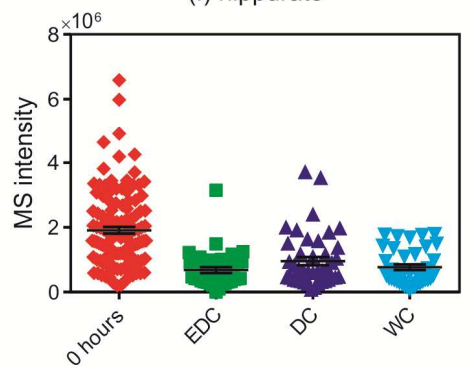

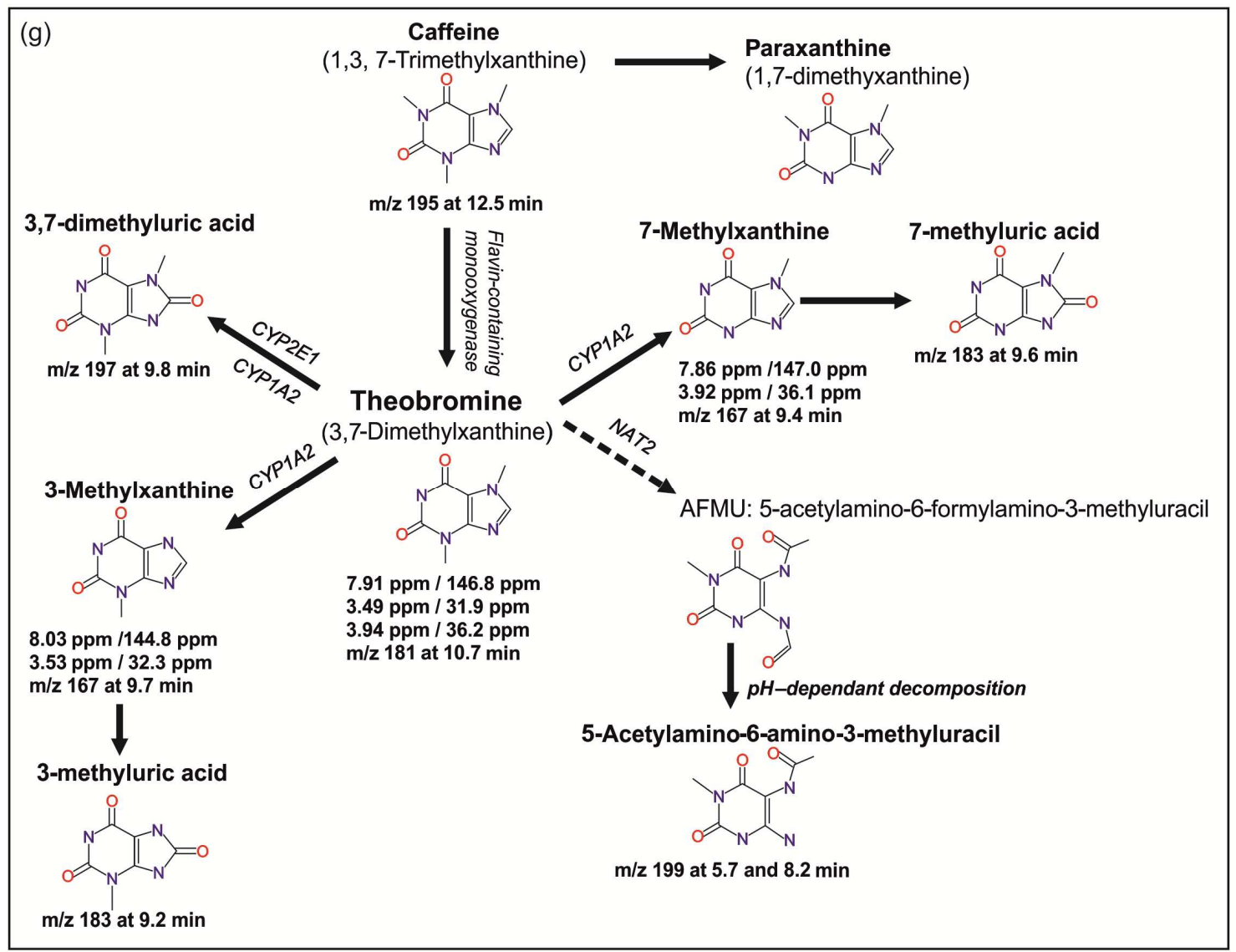

